\title{
Long-term evaluation of autologous hematopoietic stem cell transplantation in a patient with progressive systemic sclerosis
}

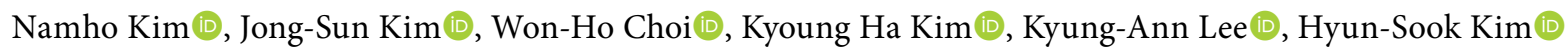 \\ Department of Internal Medicine, Soonchunhyang University Seoul Hospital, Seoul, South Korea
}

The diffuse cutaneous form of systemic sclerosis (SSc) often has a rapidly progressive course with skin hardening, which leads to involvement of the visceral organs. Although the action of autologous hematopoietic stem cell transplantation (AHSCT) is still poorly understood in autoimmune diseases, this is a promising effective treatment option for SSc patients. ${ }^{1-3}$ The European League against Rheumatism recommends AHSCT as a treatment for SSc, $\mathrm{SS}^{4,5}$ while there are few real-world case reports with long-term follow-up data. Our case was approved by the Institutional Review Board for Human Research (SCH 2020-04-013).

A 39-year-old female patient visited our clinic for uncontrolled skin thickening diagnosed in 2009. She had interstitial lung disease (ILD), discursive gastrointestinal involvement, and excessive skin hardening with a modified Rodnan skin score (mRSS) of 44 with joint contractures (Figure 1a-d). Over the past six years, she had been treated with 18 cycles of high-dose cyclophosphamide (CYC), tacrolimus, glucocorticoid, and intravenous immunoglobulin. Because she developed progressive skin hardening with contractures, AHSCT was proposed (Figure 2). To mobilize and collect peripheral stem cell progenitors, intravenous
CYC was started (a total of $4 \mathrm{~g} / \mathrm{m}^{2}$ administered in equal amounts on two days), followed by hematopoietic growth factors (granulocytecolony-stimulating factor). She underwent AHSCT with a non-myeloablative regimen and the infusion of unmanipulated blood stem cells (cluster of differentiation $34+=19.87 \times 106 / \mathrm{kg}$ ). In the transplantation phase, the conditioning regimen consisted of intravenous $\mathrm{CYC}$ for a total dose of $200 \mathrm{mg} / \mathrm{kg}$, subdivided into four equal doses from Day 5 to Day 2 before transplantation and rabbit anti-thymocyte globulin at a total dose of $6.5 \mathrm{mg} / \mathrm{kg}$ (subdivided into equal doses from Day 5 to Day 2). The patient was also given acyclovir, levofloxacin, and micafungin for infection prophylaxis. Skin thickening had improved, where the mRSS score was 22 at one year after AHSCT, 16 at two years, and 11 from three years onward (Figure 2). In March 2020, high-resolution computed tomography showed mild ground glass opacities in both lungs that had not changed from three years before. The improvements in skin tightness are shown in Figure 1.

The skin is involved in the early phase of SSc and this has a great impact on the quality of life. For a long time, CYC has been used as the standard treatment for SSc patients with thick skin and

Received: May 03, 2020 Accepted: June 15, 2020 Published online: January 14, 2021

Correspondence: Hyun-Sook Kim, MD. PhD. Department of Internal Medicine, Soonchunhyang University Seoul Hospital, 04401 Seoul, South Korea. Tel: +82 1062-5864-98 e-mail: healthyra@schmc.ac.kr 

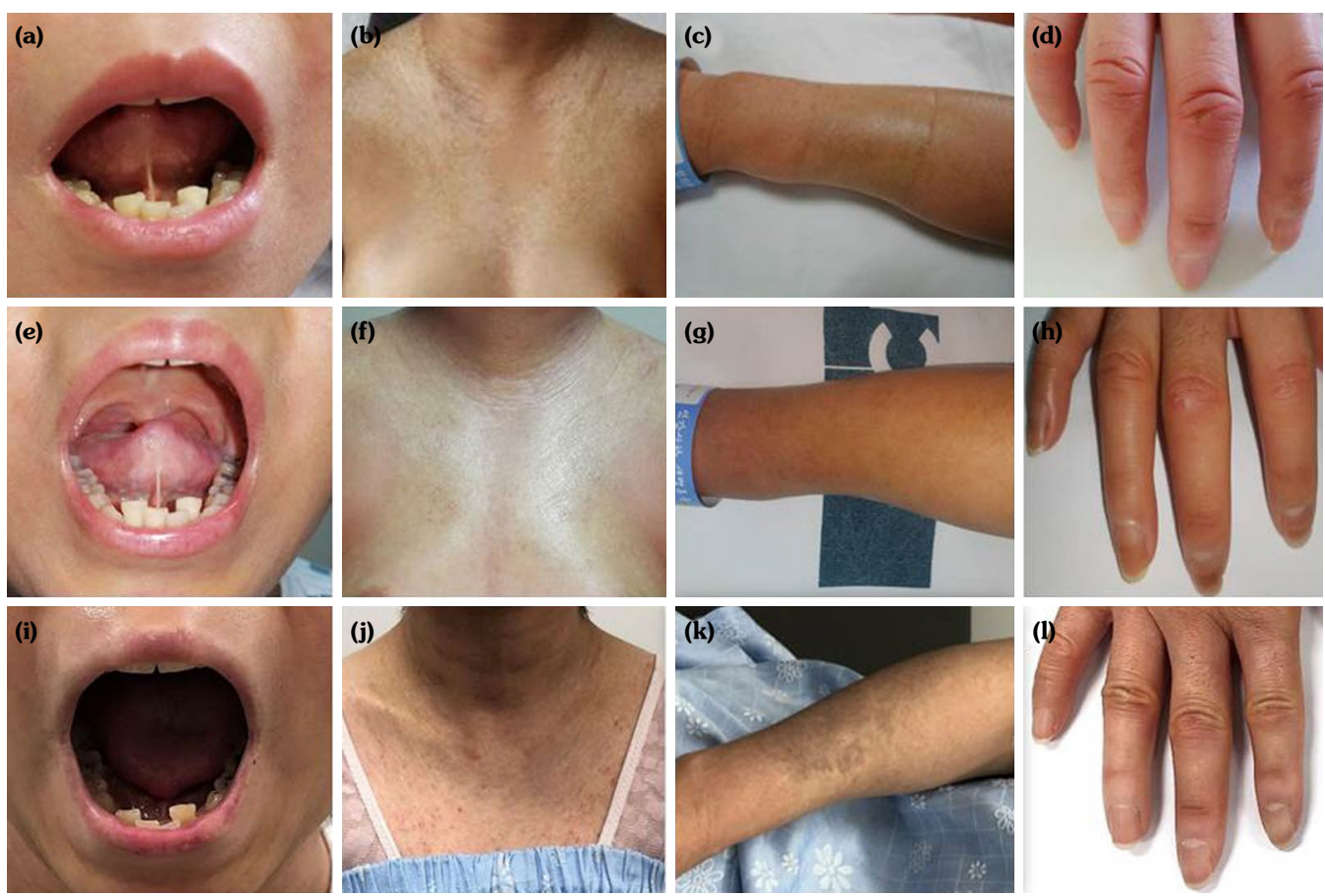

Figure 1. (a) Initially, patient had a fish mouth with fibrotic contracture of frenulum linguae and

(b) a wide range of abnormal pigmentation on anterior chest wall with diffuse fibrosis. (c) She also had contracted band-like fibrosis in forearm. (d) There was a dystrophic ulcer on third finger. (e) At 110 days after autologous hematopoietic stem cell transplantation, she could open her mouth more easily. (f, $\mathbf{g})$ Abnormal pigmentation on anterior chest wall with diffuse fibrosis and contracted band-like fibrosis of forearm had improved. (h) Dystrophic ulcer on third finger had healed and hand skin thickness had also improved. (i) At three years after autologous hematopoietic stem cell transplantation, her opening ability had improved. (j, k) Skin thickening and hardness of anterior chest wall and forearm had decreased. (l) Hand swelling had almost disappeared.

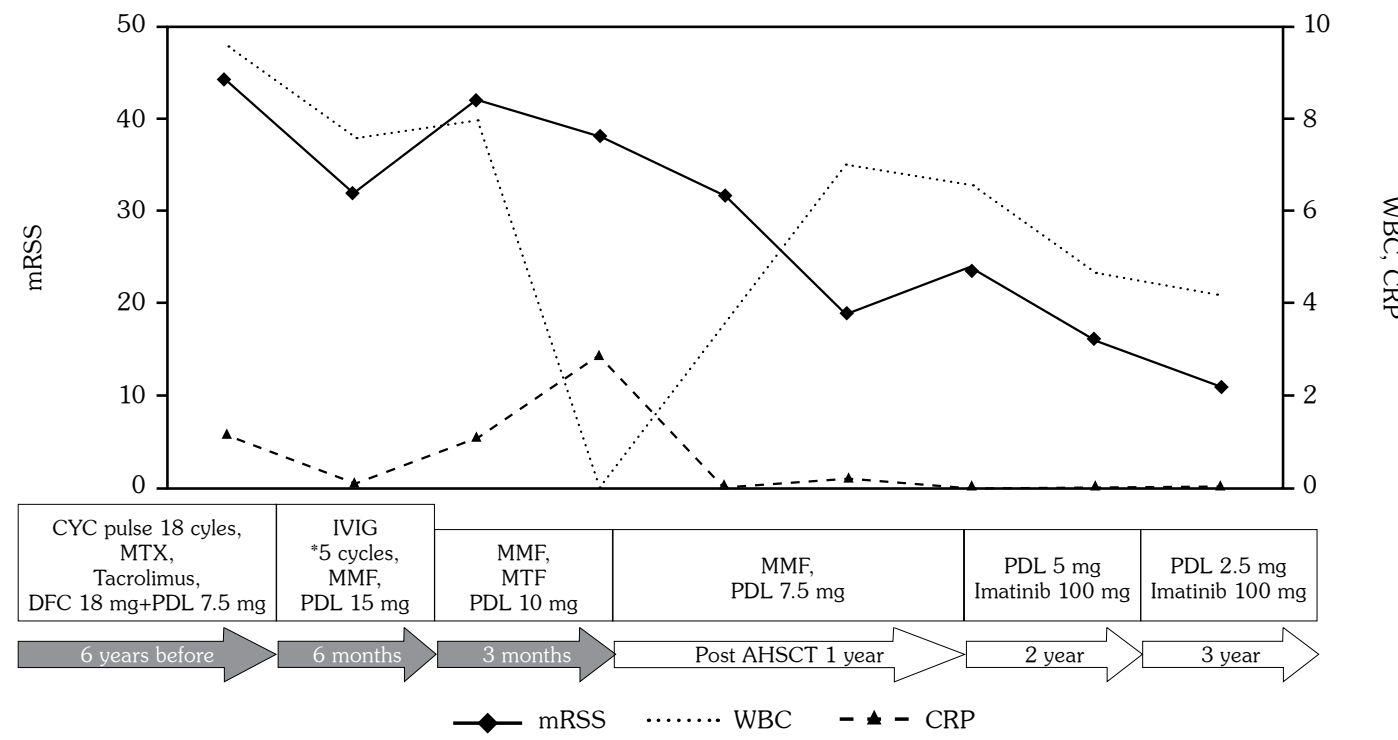

Figure 2. Patient's clinical course and treatment history.

mRSS: Modified Rodnan skin score; WBC: White blood cell; CRP: C-reactive protein; CYC: Cyclophosphamide; MTX: Methotrexate; DFC: Deflazacort; IVIG: Intravenous immunoglobulin; MMF: Mycophenolate mofetil; PDL: Prednisone; AHSCT: Autologous hematopoietic stem cell transplantation; Units: White blood cell: 103/ $\mu \mathrm{L}$; Erythrocyte sedimentation rate: $\mathrm{mm} / \mathrm{h}$; C-reactive protein: $\mathrm{mg} / \mathrm{dL}$. 
concomitant ILD. ${ }^{6}$ There is limited evidence that other immunosuppressive agents (methotrexate, azathioprine, rituximab, and mycophenolate mofetil) are effective in changing the natural course of SSc.1,7 Transplantation reflects a preference for AHSCT due to the higher related risk of graft-versus-host disease of allogeneic hematopoietic stem cell transplantation. ${ }^{8}$ The efficacy, safety, and long-term effects of AHSCT in SSc have been demonstrated in randomized controlled trials. ${ }^{4,9}$

In our case, AHSCT was performed for rapid progressive skin hardening in SSc. Although we did not achieve treatment-free remission, non-ablative AHSCT resulted in skin improvement over three years without serious side effects. In Korea, very few cases have been treated using AHSCT. In this article, we report a case of SSc treated using AHSCT, with a long-term follow-up of three years, as an example.

\section{Declaration of conflicting interests}

The authors declared no conflicts of interest with respect to the authorship and/or publication of this article.

\section{Funding}

This article was supported by the Soonchunhyang University fund.

\section{REFERENCES}

1. Del Papa N, Onida F, Zaccara E, Saporiti G, Maglione $\mathrm{W}$, Tagliaferri E, et al. Autologous hematopoietic stem cell transplantation has better outcomes than conventional therapies in patients with rapidly progressive systemic sclerosis. Bone Marrow Transplant 2017;52:53-8.

2. Cipriani P, Ruscitti P, Giacomelli R. Stem cell therapies for systemic sclerosis. Br J Haematol 2015;168:328-37.

3. Kowal-Bielecka O, Fransen J, Avouac J, Becker M, Kulak A, Allanore Y, et al. Update of EULAR recommendations for the treatment of systemic sclerosis. Ann Rheum Dis 2017;76:1327-39.

4. Sullivan KM, Goldmuntz EA, Keyes-Elstein L, McSweeney PA, Pinckney A, Welch B, et al. Myeloablative Autologous Stem-Cell Transplantation for Severe Scleroderma. N Engl J Med 2018;378:35-47.

5. Del Papa N, Pignataro F, Zaccara E, Maglione W, Minniti A. Autologous Hematopoietic Stem Cell Transplantation for Treatment of Systemic Sclerosis. Front Immunol 2018;9:2390.

6. Nannini C, West CP, Erwin PJ, Matteson EL. Effects of cyclophosphamide on pulmonary function in patients with scleroderma and interstitial lung disease: a systematic review and meta-analysis of randomized controlled trials and observational prospective cohort studies. Arthritis Res Ther 2008;10:R124.

7. van Laar JM, Farge D, Sont JK, Naraghi K, Marjanovic $Z$, Larghero J, et al. Autologous hematopoietic stem cell transplantation vs intravenous pulse cyclophosphamide in diffuse cutaneous systemic sclerosis: a randomized clinical trial. JAMA 2014;311:2490-8.

8. Tyndall A. Stem cells: HSCT for systemic sclerosis-swallows and summers. Nat Rev Rheumatol 2011;7:624-6.

9. Puyade M, Maltez N, Lansiaux P, Pugnet G, Roblot $\mathrm{P}$, Colmegna I, et al. Health-related quality of life in systemic sclerosis before and after autologous haematopoietic stem cell transplant-a systematic review. Rheumatology (Oxford) 2020;59:779-89. 